\title{
Health seeking behavior and associated factors among individuals with cough in Yiwu, China: a population-based study
}

Xiaoyan Sun ${ }^{1 \dagger}$, Shuying Luo ${ }^{1 \dagger}$, Lingqiao Lou', Hang Cheng ${ }^{1}$, Zhen Ye ${ }^{1}$, Jianwei Jia ${ }^{1}$, Yina Wei ${ }^{1}$, Jingbo Tao ${ }^{1}$ and Hanqing $\mathrm{He}^{2^{*}}$

\begin{abstract}
Background: Previous studies have shown that a certain proportion of the population did not seek medical treatment after coughing, and understanding the potential reasons is crucial for disease prevention and control.

Method: A population-based study was conducted with the probability proportional to population size sampling in Yiwu, Zhejiang, China. A total of 5855 individuals aged $\geq 15$ years lived in Yiwu for more than 6 months were included. All participants completed a laptop-based questionnaire to collect detailed information by a face-to-face interview. Characteristics of individuals were described by categories of health seeking behavior using frequency and percentage. Univariate and multivariate logistic regression analyses were performed to estimate the associations of social-demographic and cough characteristics with health seeking behavior.

Results: $19.3 \%$ (1129/5855) of participants had a cough in the past month, 40\% (452/1129) had sought medical treatment. Of these, $26.5 \%$ (120/452) chose hospitals at county level or above. Individuals aged $\geq 65$ years old $(O R=$ $2.25,95 \% \mathrm{Cl}: 1.23,4.12)$, female $(\mathrm{OR}=1.57,95 \% \mathrm{Cl}: 1.21,2.06)$, living in rural areas $(\mathrm{OR}=1.30,95 \% \mathrm{Cl}: 1.003,1.69)$, persistent cough for $3-8$ weeks ( $O R=2.91,95 \% \mathrm{Cl}: 1.72,4.92)$ and with more accompanying symptoms $\left(\mathrm{P}_{\text {trend }}<\right.$ 0.001 ) were more likely to seek medical treatment, but those coughed for $>8$ weeks were not $(p>0.5)$. Female $(\mathrm{OR}=0.33,95 \% \mathrm{Cl}: 0.21,0.54)$ and people living in rural areas $(\mathrm{OR}=0.57,95 \% \mathrm{Cl}: 0.36,0.92)$ were less likely to choose hospitals at county level or above while the higher educated were more likely to $(\mathrm{OR}=3.29,95 \% \mathrm{Cl}: 1.35$, 8.02). Those who coughed for more than 2 weeks were more likely to choose hospitals at or above the county level. But the number of accompanying symptoms does not show any significant relationship with the choice of medical facility.

Conclusion: The present study found that age, sex, living areas and features of cough were associated with health seeking behavior. It is worth noting that those who coughed for too long (e.g. > 8 weeks) were less likely to seek medical treatment. Targeted measures should be developed based on the key factors found in this study to guide persons to seek medical treatment more scientifically.
\end{abstract}

Keywords: Cough, Health seeking decision, Choice of medical facility

\footnotetext{
* Correspondence: hanqinghe@cdc.zj.cn

${ }^{\dagger}$ Xiaoyan Sun and Shuying Luo contributed equally to this work.

${ }^{2}$ Zhejiang Provincial Center for Disease Control and Prevention, Hangzhou

310051, P.R. China

Full list of author information is available at the end of the article
}

(c) The Author(s). 2021 Open Access This article is licensed under a Creative Commons Attribution 4.0 International License, which permits use, sharing, adaptation, distribution and reproduction in any medium or format, as long as you give appropriate credit to the original author(s) and the source, provide a link to the Creative Commons licence, and indicate if changes were made. The images or other third party material in this article are included in the article's Creative Commons licence, unless indicated otherwise in a credit line to the material. If material is not included in the article's Creative Commons licence and your intended use is not permitted by statutory regulation or exceeds the permitted use, you will need to obtain permission directly from the copyright holder. To view a copy of this licence, visit http://creativecommons.org/licenses/by/4.0/ The Creative Commons Public Domain Dedication waiver (http://creativecommons.org/publicdomain/zero/1.0/) applies to the data made available in this article, unless otherwise stated in a credit line to the data. 


\section{Background}

Cough is an essential defensive mechanism. It is not only a common symptom of respiratory diseases but also can reflect significant diseases [1, 2]. More importantly, cough is an important factor in the spread of respiratory infectious diseases $[3,4]$. According to the International Standards for Tuberculosis Care, all persons with otherwise unexplained productive cough lasting 2-3 weeks or more should be evaluated for tuberculosis $[5,6]$. Recent studies also found that pertussis characterized by persistent cough is more prevalent in some areas, with a prevalence of $10.9-24.5 \%$ [7-9]. In China, the prevalence of cough fluctuates between 9 and 64\%, highlight the level of significance and the corresponding burden of disease cannot be underestimated [10]. Thus scientific health seeking behavior of patients with cough is of great importance, which is conducive to the early diagnosis and treatment of diseases, especially contribute to the promptly prevention and control of respiratory infectious diseases.

However, previous studies found that a high proportion of patients who did not seek medical treatment after cough, and socio-demographic charactersistics were associated with health-seeking decision [11-13]. However, most of them were conducted abroad and found that evidence describing the potential risk factors are heterogeneous. A risk factor in one setting may promote the health-seeking decision but not in other settings. For example, a Ethiopia study found that higher income group were more likely to seek medical service [14], while studies in South African [12] and Zambia [15] showed an opposite association for the same risk factor, and study in India [16] found there was no correlation between income and health-seeking decision. The same situation occurs in other risk factors, such as age, sex, occupation and smoking status [13, 15, 17-19]. Besides, some factors were studied extensively in many studies (namely age, sex, education, occupation and income) while others may only appear in very few studies (namely, features of cough) [13, 20]. What'more, there is still no study has focused on the association between the duration of a cough and health seeking behavior.

Besides, studies on the choice of medical facilities for individuals with cough is very limited. In China, only very few studies have conducted at health facility level and focused on the individuals with presumptive tuberculosis [21-23].

Here, a community survey provided us with a unique opportunity to look at the health seeking behavior of individuals with cough. The aim of the present study was to describe the health seeking behaviors (including health-seeking decision and choice of medical facility) of individuals with cough, and to examine the associations of social-demographic characteristics and features of cough with health seeking behavior.

\section{Methods \\ Study design and population}

A cross-sectional survey was conducted in Yiwu-a county-level city of about 2,000,000 people-situated in the central Zhejiang Province of China. All individuals aged $\geq 15$ years and were living in Yiwu for more than 6 months during the months of October to December 2019 were considered as the source population.

Fifty clusters were selected from 14 town/streets in Yiwu with the probability proportional to population size sampling method, followed by a quota sampling method based on age and sex to select 110 individuals from each cluster. Then well-trained investigators went to each cluster to interview individuals who met the above criteria through simple random sampling.

All individuals completed a laptop-based questionnaire to collect detailed information by a face-to-face interview after signing the informed consent. Any impermanent residents from the sampled village (residential community) who lived in Yiwu for less than 6 months were excluded. If there were two or more eligible people from one family, only one was randomly selected to participate in the survey. Individuals who have had a cough in the past month were included in the present study.

\section{Study questionnaire}

We used a 12-item questionnaire to ask the cough status and health seeking behavior of the participants. The questionnaire was further revised after discussion and revision by the project team experts and on-site preinvestigation before it was officially used. Besides, logical verification was carried out in the design to avoid filling errors and missing information. The questionnaire consists of two parts. The first part included the basic information of participants, including age, sex, ethnic, occupation, education, family size, income, smoking status and history of chronic disease. The second part included the participants' cough status in the past month, whether they went to a doctor because of the most recent cough, and which medical institution has been chosen. See additional files for details.

\section{Measurement}

\section{Assessment of cough and health seeking behavior}

Cough was assessed by asking participants "Have you had a cough during the past month". If the participants answered "Yes", they were further asked the cough duration and whether they had accompanying symptoms, such as fever, expectoration, sore throat, runny nose, dyspnea, headache, fatigue, lethargy, earache, muscle or 
joint pain, abdominal pain, shortness of breath, chest pain, irritability and others. We categorized the duration of cough period into $\leq 2$ weeks, $3-8$ weeks and $>8$ weeks, and defined $\leq 2$ weeks as the reference group. And numbers of accompanying symptoms into 3 groups, namely 0 (reference), 1, 2 and above.

In the present study, we defined health seeking behavior as health-seeking decision and choice of medical facility. Participants were asked "Did you go to a medical facility for treatment duringyour last cough (not limited to the past month)?" to acquire their health-seeking decision. If the participants answered "Yes", they were further asked "which medical facility did you choose". Options include clinics, 14 township hospitals or community health service centers, municipal hospitals, and others (open answer). We categorized the choice of medical facility into hospitals at county level or above and community health service center or below.

\section{Other covariates}

Other covariates including age (15-24, 25-64, $\geq 65$ years old), sex, living areas (rural or urban), level of education (primary school or below, middle/high school, college or above), occupation (student, unemployment, business and services, professionals, farmers and workers), household income $(<100,000,100,000-199,999$ and $\geq 200,000$ yuan per year), children under 5 years old (yes or no), and current smoking status (yes or no). Besides, they were further asked if they had a history of chronic diseases (yes or no) by question "whether you have the following chronic diseases: hypertension, cardiovascular and cerebrovascular diseases, diabetes, chronic diseases of ear, nose and throat, chronic respiratory diseases, digestive diseases, and others".

\section{Statistical analysis}

Socio-demographic characteristics of participants were described using frequency and percentage. Both univariate and multivariate logistic regression analyses were performed to estimate the associations of socialdemographic characteristics and features of cough with health-seeking decision or choice of health facilities. All variables in the bivariate analyses were included in the multivariate analysis utilsing binary logistic regression analysis with enter process. All statistical analyses were conducted using SPSS 19.0 statistical software and all $p$ values refer to two-tailed tests. Statistical significance was set at $P<0.05$.

\section{Results}

\section{Characteristics of study population}

A total of 5860 respondents participated in the interviews, of which 5 were excluded because they did not complete the survey.
Of 5855 eligible individuals interviewed, $69.6 \%$ of individuals aged $25-64$ years old, $10.8 \%$ were $\geq 65$ years old, $50.7 \%$ were females and $40.0 \%$ living in rural areas. Around half had attended middle school, $22.7 \%$ graduated from college and above. 1129 (19.3\%) reported coughing in the past month. Detailed characteristics of individuals are shown in Table 1.

\section{Factors associated with health-seeking decision}

Of the 1129 participants who reported coughing in the past month, 40\% (452) had been to medical facilities. The associations of socio-demographic characteristics and features of cough with health-seeking decision are presented in Table 2. Participants who aged $\geq 65$ years old, female and living in rural areas were associated 2.26 (95\% CI: 1.24, 4.14), 1.57 (95\% CI: 1.21, 2.07) and 1.31 (95\% CI: $1.01,1.70)$ times greater likelihood of seeking medical treatment respectively. Compared with individuals coughed for $\leq 2$ weeks, those coughed for 3-8 weeks was 2.81 (95\% CI: 1.68, 4.73) times more likely to seek medical treatment. However, there was no significant difference between those coughed for more than 8 weeks and less than 2 weeks. A significant positive trend $(P<0.001)$ was observed between the number of accompanying symptoms and health-seeking decision. Compared with participants who reported no accompanying symptoms with cough, those reported symptoms were more likely to seek medical treatment, particularly for those with two symptoms and above $(\mathrm{OR}=3.87,95 \% \mathrm{CI}: 2.74,5.47)$.

\section{Factors associated with choice of medical facility}

Of the 452 participants who went for medical treatment, $120(26.5 \%)$ chose hospitals at county level or above. The associations of socio-demographic characteristics and features of cough with choice of medical facility are presented in Table 3. Female and people live in rural areas were 0.33 (95\% CI: 0.21 , $0.54)$ and 0.57 (95\% CI: 0.36, 0.92) times less likely to choose hospitals at county level or above respectively. Individuals with college degree or above were more likely to seek medical treatment in hospitals at or above the county level compared to those with education below primary school $(\mathrm{OR}=3.29,95 \% \mathrm{CI}$ : $1.35,8.02)$. Participants who coughed for $3-8$ weeks and $>8$ weeks were associated with a higher likelihood of choosing hospitals at or above the county level $(\mathrm{OR}=2.35,95 \% \mathrm{CI}: 1.19,4.61, \mathrm{OR}=3.13,95 \%$ CI: $1.24,7.90$, respectively). Number of accompanying symptoms does not show significant relationship with choosing medical facility.

\section{Discussion}

To the best of our knowledge, the present study is the first community-based study focused on the association of 
Table 1 Socio-demographic characteristics of the total population and individuals with cough in the past month

\begin{tabular}{|c|c|c|c|c|}
\hline \multirow[t]{2}{*}{ Characteristics } & \multicolumn{2}{|c|}{ Total population } & \multicolumn{2}{|c|}{ Individuals with cough } \\
\hline & $\mathbf{N}$ & $\%$ & $\mathrm{~N}$ & $\%$ \\
\hline Total & 5855 & 100 & 1129 & 19.3 \\
\hline \multicolumn{5}{|l|}{ Age (years) } \\
\hline $15-24 y$ & 1146 & 19.6 & 245 & 21.4 \\
\hline $25-64 y$ & 4078 & 69.6 & 684 & 16.8 \\
\hline$\geq 65 y$ & 631 & 10.8 & 200 & 31.7 \\
\hline \multicolumn{5}{|l|}{ Residence } \\
\hline Urban & 3512 & 60.0 & 671 & 19.1 \\
\hline Rural & 2343 & 40.0 & 458 & 19.5 \\
\hline \multicolumn{5}{|l|}{ Sex } \\
\hline Male & 2887 & 49.3 & 576 & 20 \\
\hline Female & 2968 & 50.7 & 553 & 18.6 \\
\hline \multicolumn{5}{|l|}{ Occupation } \\
\hline Student & 335 & 5.7 & 104 & 31 \\
\hline Unemployed & 1461 & 25.0 & 337 & 23.1 \\
\hline Business/service & 2104 & 35.9 & 314 & 14.9 \\
\hline Professional & 1247 & 21.3 & 232 & 18.6 \\
\hline Farmers and workers & 708 & 12.1 & 142 & 20.1 \\
\hline \multicolumn{5}{|l|}{ Education } \\
\hline Primary school and below & 1267 & 21.6 & 309 & 24.4 \\
\hline Middle school & 3261 & 55.7 & 531 & 16.3 \\
\hline College and above & 1327 & 22.7 & 289 & 21.8 \\
\hline \multicolumn{5}{|l|}{ Child under 5 years old } \\
\hline No & 3450 & 58.9 & 708 & 20.5 \\
\hline Yes & 2405 & 41.1 & 421 & 17.5 \\
\hline \multicolumn{5}{|l|}{ Income (yuan) ${ }^{a}$} \\
\hline$<100,000$ & 3372 & 57.6 & 667 & 19.8 \\
\hline $100,000-199,999$ & 1772 & 30.3 & 331 & 18.7 \\
\hline$\geq 200,000$ & 710 & 12.1 & 130 & 18.3 \\
\hline \multicolumn{5}{|l|}{ Smoking status ${ }^{a}$} \\
\hline No & 3249 & 55.5 & 592 & 18.2 \\
\hline Yes & 2605 & 44.5 & 537 & 20.6 \\
\hline \multicolumn{5}{|l|}{ Chronic disease } \\
\hline No & 4695 & 80.2 & 783 & 16.7 \\
\hline Yes & 1160 & 19.8 & 346 & 29.8 \\
\hline
\end{tabular}

${ }^{a}$ Missing data for one individual

socio-demographic and cough characteristics with health seeking behavior in the Chinese population. We found that $19.3 \%(n=5855)$ of the respondents reported a cough in the past month, $40 \%(n=1129)$ of them had sought medical treatment. Individuals more than 65 years old, female, with cough for 3-8 weeks and with more accompanying symptoms were more likely to seek medical treatment. For those had sought medical treatment, $26.5 \%(n=462)$ chose hospitals at county level or above. Male, people live in urban areas, individuals graduated from college and above and with cough for more than 2 weeks were more likely to choose hospitals at county level or above.

\section{Health-seeking decision}

Contrary to some previous studies on health-seeking behavior $[12,14,15]$, we found that some of the sociodemographic characteristics, such as education, occupation, family size and household income do not seem to 
Table 2 Univariate and multivariate logistic regression analysis for health-seeking decision after coughing $(N=1129)$

\begin{tabular}{|c|c|c|c|c|c|}
\hline \multirow[t]{2}{*}{ Characteristics } & \multirow{2}{*}{$\begin{array}{l}\text { Seeking } \\
\text { treatment } \\
\mathrm{N}(\%)\end{array}$} & \multicolumn{2}{|l|}{ Univariable } & \multicolumn{2}{|l|}{ Multivariable } \\
\hline & & Crude OR & $P$ value & Adjusted OR & $P$ value \\
\hline \multicolumn{6}{|l|}{ Age } \\
\hline $15-24 y$ & $86(35.1)$ & Ref & & Ref & \\
\hline $25-64 y$ & $267(39.0)$ & $1.18(0.87,1.16)$ & 0.277 & $1.44(0.95,2.19)$ & 0.089 \\
\hline$\geq 65 y$ & $99(49.5)$ & $1.81(1.24,2.65)$ & 0.002 & $2.26(1.24,4.14)$ & 0.008 \\
\hline \multicolumn{6}{|l|}{ Residence } \\
\hline Urban & $247(36.8)$ & Ref & & Ref & \\
\hline Rural & $205(44.8)$ & $1.39(1.09,1.77)$ & 0.008 & $1.31(1.01,1.70)$ & 0.044 \\
\hline \multicolumn{6}{|l|}{ Sex } \\
\hline Male & $195(33.9)$ & Ref & & Ref & \\
\hline Female & $257(46.5)$ & $1.70(1.33,2.16)$ & $<0.001$ & $1.57(1.21,2.07)$ & 0.001 \\
\hline \multicolumn{6}{|l|}{ Occupation } \\
\hline Student & $40(38.5)$ & Ref & & Ref & \\
\hline Unemployed & $154(45.7)$ & $1.35(0.86,2.11)$ & 0.195 & $1.18(0.61,2.29)$ & 0.628 \\
\hline Business/service & $103(32.8)$ & $0.78(0.49,1.24)$ & 0.292 & $0.98(0.52,1.84)$ & 0.945 \\
\hline Professional & $101(43.5)$ & $1.23(0.77,1.98)$ & 0.384 & $1.34(0.71,2.53)$ & 0.364 \\
\hline Farmers and workers & $54(38.0)$ & $0.98(0.58,1.65)$ & 0.945 & $1.18(0.57,2.45)$ & 0.654 \\
\hline \multicolumn{6}{|l|}{ Education } \\
\hline Primary school and below & $134(43.4)$ & Ref & & Ref & \\
\hline Middle school & $225(38.7)$ & $0.83(0.62,1.09)$ & 0.179 & $1.35(0.92,1.98)$ & 0.127 \\
\hline College and above & $93(38.9)$ & $0.83(0.59,1.17)$ & 0.294 & $1.14(0.70,1.86)$ & 0.605 \\
\hline \multicolumn{6}{|l|}{ Child under 5 years old } \\
\hline No & $290(41.0)$ & Ref & & & \\
\hline Yes & $162(38.5)$ & $0.90(0.70,1.15)$ & 0.411 & $0.97(0.72,1.30)$ & 0.829 \\
\hline \multicolumn{6}{|l|}{ Income (yuan) } \\
\hline$<100,000$ & $270(40.5)$ & Ref & & Ref & \\
\hline $100,000-199,999$ & $134(40.5)$ & $1.00(0.77,131)$ & 0.999 & $1.08(0.79,1.48)$ & 0.644 \\
\hline$\geq 200,000$ & $47(36.2)$ & $0.83(0.56,1.23)$ & 0.357 & $0.99(0.63,1.56)$ & 0.968 \\
\hline \multicolumn{6}{|l|}{ Smoking status } \\
\hline No & $260(43.9)$ & Ref & & Ref & \\
\hline Yes & $192(35.8)$ & $0.71(0.56,0.90)$ & 0.005 & $0.81(0.62,1.06)$ & 0.126 \\
\hline \multicolumn{6}{|l|}{ Chronic disease } \\
\hline No & $285(36.4)$ & Ref & & Ref & \\
\hline Yes & $167(48.3)$ & $1.63(1.26,2.11)$ & $<0.001$ & $1.28(0.93,1.77)$ & 0.128 \\
\hline \multicolumn{6}{|l|}{ Duration of cough (week) } \\
\hline$\leq 2$ & $372(37.5)$ & Ref & & Ref & \\
\hline $3-8$ & $56(68.3)$ & $3.59(2.22,5.82)$ & $<0.001$ & $2.81(1.68,4.73)$ & $<0.001$ \\
\hline$>8$ & $24(43.6)$ & $1.29(0.75,2.23)$ & 0.362 & $1.26(0.70,2.26)$ & 0.448 \\
\hline \multicolumn{6}{|c|}{ Number of accompanying symptoms } \\
\hline 0 & $96(24.9)$ & Ref & & & \\
\hline 1 & $179(42.1)$ & $2.19(1.62,2.96)$ & $<0.001$ & $2.19(1.59,3.01)$ & $<0.001$ \\
\hline$\geq 2$ & $177(55.5)$ & $3.75(2.73,5.17)$ & $<0.001$ & $3.87(2.74,5.47)$ & $<0.001$ \\
\hline
\end{tabular}


Table 3 Univariate and multivariate logistic regression analysis for choice of medical facility after coughing $(N=452)$

\begin{tabular}{lll}
\hline Characteristics & \multicolumn{2}{l}{ Choice of Medical Facility } \\
\cline { 2 - 3 } & $\begin{array}{l}\text { Community health service center and } \\
\text { below N (\%) }\end{array}$ & $\begin{array}{l}\text { hospital } \\
\text { above N }\end{array}$ \\
\hline Age & $61(70.9)$ & $25(29.1)$ \\
$15-24 y$ & $207(77.5)$ & $60(22.5)$ \\
$25-64 y$ & & $35(35.4)$ \\
$\geq 65 y$ & $64(64.6)$ &
\end{tabular}

\section{Crude OR $P$ value Adjusted}

OR

at county level and

\section{Residence}

$\begin{array}{lll}\text { Urban } & 162(65.6) & 85(34.4) \\ \text { Rural } & 170(82.9) & 35(17.1)\end{array}$

Sex

$\begin{array}{lll}\text { Male } & 135(69.2) & 60(30.8) \\ \text { Female } & 197(76.7) & 60(23.3)\end{array}$

Occupation

\begin{tabular}{|c|c|}
\hline Student & $27(67.5)$ \\
\hline Unemployed & $112(7$ \\
\hline $\begin{array}{l}\text { Business/service } \\
\text { personnel }\end{array}$ & $76(73$ \\
\hline Professional & $78(77$ \\
\hline $\begin{array}{l}\text { Farmers and } \\
\text { workers }\end{array}$ & $39(7$ \\
\hline
\end{tabular}

\section{Education}

Primary school and 99 (73.9) below

Middle school $171(76)$

College and above 62 (66.7)

\section{Child under 5}

$\begin{array}{ll}\text { No } & 206(71) \\ \text { Yes } & 126(77.8)\end{array}$

\section{Household income (yuan)}

$$
\begin{array}{ll}
<100,000 & 203(75.2) \\
100,000-199,999 & 100(74.6) \\
\geq 200,000 & 28(59.6)
\end{array}
$$

\section{Smoking status}

$\begin{array}{ll}\text { No } & 184(70.8) \\ \text { Yes } & 148(77.1)\end{array}$

\section{Chronic disease}

$\begin{array}{ll}\text { No } & 210(73.7) \\ \text { Yes } & 122(73.1)\end{array}$
$35(26.1)$
54 (24)
$13(32.5)$
$42(27.3)$
$27(26.2)$
$23(22.8)$
$15(27.8)$
$31(33.3)$

84 (29)

$36(22.2)$

67 (24.8)

34 (25.4)

$19(40.4)$

76 (29.2)

$44(22.9)$

75 (26.3)

$45(26.9)$
Ref Ref

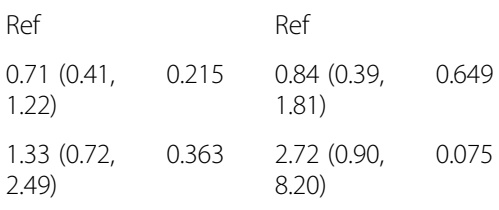

Ref Ref

$0.39(0.25,<0.001 \quad 0.33(0.21,<0.001$

$0.62) \quad 0.54)$

Ref Ref

$\begin{array}{llll}0.69(0.45, & 0.077 & \mathbf{0 . 5 7}(\mathbf{0 . 3 6}, & \mathbf{0 . 0 2 1} \\ 1.04) & & \mathbf{0 . 9 2})\end{array}$

$0.78(0.37, \quad 0.514 \quad 0.73(0.22, \quad 0.61$

1.65) 2.41)

$\begin{array}{llll}0.74(0.33, & 0.453 & 0.65(0.21, & 0.457\end{array}$

1.63) 2.04)

$0.61(0.27, \quad 0.235 \quad 0.43(0.14, \quad 0.137$

1.38) 1.31)

$0.80(0.33, \quad 0.621 \quad 0.74(0.20, \quad 0.659$

1.95) 2.80)

Ref Ref

$0.89\left(\begin{array}{llll}0.55, & 0.653 & 1.44(0.69, & 0.332\end{array}\right.$

1.46) 3.01)

$\begin{array}{llll}1.41(0.79, & 0.24 & \mathbf{3 . 2 9}(\mathbf{1 . 3 5}, \quad \mathbf{0 . 0 0 9}\end{array}$

2.52) 8.02)

Ref $\quad$ Ref

$0.70(0.45, \quad 0.12 \quad 0.75(0.42, \quad 0.33$

1.10) 1.34)

Ref Ref

$1.03(0.64, \quad 0.903 \quad 0.98(0.55, \quad 0.937$

1.66) 1.75)

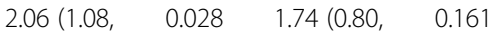

$3.92) \quad 3.79)$

Ref Ref

$0.72(0.47, \quad 0.134 \quad 0.73(0.45, \quad 0.193$

1.11) 1.18)

Ref Ref

$1.03(0.67, \quad 0.884 \quad 0.63(0.35, \quad 0.123$ 
Table 3 Univariate and multivariate logistic regression analysis for choice of medical facility after coughing ( $N=452)(C o n t i n u e d)$

\begin{tabular}{|c|c|c|c|c|c|c|}
\hline \multirow[t]{2}{*}{ Characteristics } & \multicolumn{2}{|l|}{ Choice of Medical Facility } & \multirow[t]{2}{*}{ Crude OR } & \multirow[t]{2}{*}{$P$ value } & \multirow{2}{*}{$\begin{array}{l}\text { Adjusted } \\
\text { OR }\end{array}$} & \multirow[t]{2}{*}{$P$ value } \\
\hline & $\begin{array}{l}\text { Community health service center and } \\
\text { below } \mathrm{N}(\%)\end{array}$ & $\begin{array}{l}\text { hospital at county level and } \\
\text { above } N(\%)\end{array}$ & & & & \\
\hline & & & 1.59) & & 1.14) & \\
\hline \multicolumn{7}{|c|}{ Duration of cough (week) } \\
\hline$\leq 2$ & $284(76.3)$ & $88(23.7)$ & Ref & & Ref & \\
\hline $3-8$ & $35(62.5)$ & $21(37.5)$ & $\begin{array}{l}1.94(1.07 \\
3.50)\end{array}$ & 0.029 & $\begin{array}{l}2.35(1.19, \\
4.61)\end{array}$ & 0.014 \\
\hline$>8$ & $13(54.2)$ & $11(45.8)$ & $\begin{array}{l}2.73(1.18 \\
6.31)\end{array}$ & 0.019 & $\begin{array}{l}3.13(1.24, \\
7.90)\end{array}$ & 0.016 \\
\hline \multicolumn{7}{|c|}{ Number of accompanying symptoms } \\
\hline 0 & $69(71.9)$ & $27(28.1)$ & Ref & & Ref & \\
\hline 1 & $131(73.2)$ & $48(26.8)$ & $\begin{array}{l}0.94(0.54 \\
1.63)\end{array}$ & 0.816 & $\begin{array}{l}1.25(0.66 \\
2.36)\end{array}$ & 0.502 \\
\hline$\geq 2$ & $132(74.6)$ & $45(25.4)$ & $\begin{array}{l}0.87(0.50 \\
1.52)\end{array}$ & 0.629 & $\begin{array}{l}1.14(0.59 \\
2.18)\end{array}$ & 0.704 \\
\hline
\end{tabular}

be associated with the probability of seeking medical treatment after coughing. These may be related to population selection, and heterogeneity in different countries.

We also found that smokers were less likely to seek medical treatment in the univariate analysis, but the association became insignificantly after adjusting for factors such as age and duration of cough. Results of existing studies on the association between them after coughing were inconsistent $[12,14,18]$, this may be due to different confounding factors adjusted in the model, and the characteristics of cough were not included in the multivariate analysis in most studies. Although the current research results were inconsistent, given the smoking rate in China [24], this is still a very worrying and important finding, suggesting that attention should be paid to the health seeking behavior of smokers after coughing, which may also contribute to the early diagnosis and treatment of lung cancer.

The present study found that individuals aged $\geq 65$ years old and living in rural areas were more likely to seek medical treatment. Besides, women were more likely to seek medical treatment than men, which is in parallel with studies conducted in Zambia and Vietnam $[15,25]$. This may be explained by the fact that women were more troubled by cough than men [26, 27]. What's more, some studies focusing on sex differences in health-seeking behavior have pointed out that men were more likely to behave masculinity and a healthy state thus less likely to seek care [28].

The present study was the first to focus on the association between cough duration and health-seeking decision in China. A study in Finnish found that people with subacute and chronic coughs were more likely to seek medical attention [29]. However, in the present study, we found individuals with cough for 3-8 weeks were more likely to seek medical treatment, while those coughed for $>8$ weeks were not. The possible explanation for this phenomenon could be that individuals who have been coughing for $>8$ weeks were already used to coughing and regard it as a lifestyle habit rather than a disease. However, in addition to common causes of chronic cough, recent studies have found that pertussis has became a prevalent disease in some areas [7, 8], and B. pertussis infection should be considered as a significant pathogenic infection in adult patients presenting a cough of more than 3 weeks duration [30, 31]. Tuberculosis also should be evaluated among persons with unexplained productive cough lasting 2-3 weeks or more [6]. Thus there is no doubt that prolonged coughing without seeking medical treatment timely will bring an increased risk of transmission of such respiratory infectious disease. It is extremely desirable to undertake extensive educational campaigns about cough especially persistent one, so as to encourage individuals to visit medical facilities in time.

What's more, the number of accompanying symptoms showed a clear increasing trend with health-seeking decision, as were observed in India and Tanzania [13, 20]. Coughing is generally considered to be a very common symptom rather than a disease, people do not usually seek medical care if a cough is not distressing or associated with any other symptoms that restrict one's ability to function/work [32, 33]. Recent studies further demonstrated that an impaired cough-related quality of life is the most important determinant of the decision to visit a doctor due to cough $[29,34]$.

\section{Choice of medical facility}

In the present study, the multivariate analysis consistently show that individuals living in rural areas and 
women were less likely to choose hospitals at or above the county level, while the most educated persons were more likely. Studies conducted in Vietnam [25] and China $[23,35]$ also found that women took more healthcare actions than men, but chose less qualified providers (like self-medication, pharmacist, or private practitioner) and individuals living in rural areas had poor access to medical facility. But contrary to previous studies conducted in China [21, 22, 36], the household income was not significant associated with the choice of medical facility after adjusting for other confounders in the present study. This change may be due to a decline in health spending variance as the economy develops, with rising living standards and incomes.

We also found that individuals who coughed for more than 2 weeks were associated with a higher likelihood of choosing hospitals at or above the county level, while number of accompanying symptoms did not show any significant relationship with their choice. This reveals an interesting fact that people were more likely to seek medical treatment when the accompany symptoms of cough appear, but pay more attention to the duration of cough when choosing a hospital. The result echoes a call in a Japanese study [37], which suggested that individuals suffering from cough that does not resolve within a short period of time should be taken seriously regardless of the severity, as cough can be a sign of serious diseases such as lung cancer, pertussis and pulmonary tuberculosis [2, $38,39]$. Based on the fact, it is recommended to strengthen the training of relevant personnel in such facilities to improve their attention to persistent cough, as well as the level of surveillance and case detection of the above serious diseases.

\section{Limitations}

Although the data in the present study was based on a community-based population and corrected for established and potential confounding factors (both sociodemographic and cough characteristics), these findings should also be interpreted in light of some limitations. First, it is important to acknowledge the limitations of the subjective perceptions and self-reports and therefore may lead to recall bias or be biased by potential underreporting or over-reporting. Second, due to the limited sample size, some significant positive associations may not be demonstrated in the present study. Third, no respondents' refusal was captured during the conduct of the survey, that may lead to a higher response rate than other survey. Finally, the study cannot exclude the effects of residual confounding by unmeasured risk factors, such as medical insurance and cause of cough. Therefore, larger sample size studies with more adjusted confounders are warranted to examine the further association and make a firm complement to the current study.

\section{Conclusion}

The present study found that $40 \%$ of individuals sought medical treatment after cough and of these, about $1 / 3$ chose hospitals at county level or above. Age, sex, living areas, education level as well as features of cough were associated with health seeking behavior. Targeted intervention measures should be formulated based on the above key factors to guide people to seek medical treatment scientifically and rationally.

\section{Supplementary Information}

The online version contains supplementary material available at https://doi. org/10.1186/s12889-021-11250-5.

Additional file 1. Questionnaire.

\section{Acknowledgements}

We sincerely thank Dr. Jianxin Yu (Chinese Center for Disease Control and Prevention) for his help to design this study.

\section{Authors' contributions}

XS, LL, HC, ZY, JJ, YW, JT performed data collection and collation. XS performed data analysis and interpreted results. XS and SL participated in writing and editing the manuscript, and $\mathrm{HH}$ helped revise manuscript. All authors read and approved the final manuscript.

\section{Funding}

The work was supported by the following grants: National Natural Science Foundation of China (NSFC) [grant number 81973106], Beijing Municipal Natural Science Foundation [grant number 19 L2060]. The funding agency provided guidance on the design of the study and collection, analysis, and interpretation of data.

\section{Availability of data and materials}

The datasets used and/or analyzed during the current study are available from the corresponding author on reasonable request.

\section{Declarations}

Ethics approval and consent to participate

The Ethical Review Committee of the Chinese Center for Disease Control and Prevention (Beijing, China) approved the study. All the participants provided written informed consent.

Consent for publication

Not applicable.

\section{Competing interests}

The authors declare that they have no competing interest.

\section{Author details}

${ }^{1}$ Yiwu Center for Disease Control and Prevention, Yiwu 322000, P.R. China. ${ }^{2} Z$ hejiang Provincial Center for Disease Control and Prevention, Hangzhou 310051, P.R. China.

Received: 22 September 2020 Accepted: 10 June 2021

Published online: 16 June 2021

\section{References}

1. Bulgiba AM, Razaz M. How well can signs and symptoms predict AMI in the Malaysian population? Int J Cardiol. 2005;102(1):87-93. https://doi.org/10.101 6/j.jijcard.2004.04.002. 
2. Holzinger $F$, Beck $S$, Dini $L$, et al. The diagnosis and treatment of acute cough in adults. Dtsch Arztebl Int. 2014;111(20):356-63. https://doi.org/1 0.3238/arztebl.2014.0356.

3. Cho SH, Lin HC, Ghoshal AG, Bin Abdul Muttalif AR, Thanaviratananich S, Bagga $S$, et al. Respiratory disease in the Asia-Pacific region: cough as a key symptom. Allergy Asthma Proc. 2016;37(2):131-40. https://doi.org/10.2 500/aap.2016.37.3925.

4. Edwards KM. Is pertussis a frequent cause of cough in adolescents and adults? Should routine pertussis immunization be recommended? Clin Infect Dis. 2001;32(12):1698-9. https://doi.org/10.1086/320762.

5. Treatment of Tuberculosis: Guidelines. 4th ed. Geneva: World Health Organization; 2010. PMID: 23741786.

6. Hopewell PC, Pai M, Maher D, Uplekar M, Raviglione MC. International standards for tuberculosis care. Lancet Infect Dis. 2006;6(11):710-25. https:// doi.org/10.1016/S1473-3099(06)70628-4.

7. Hu JJ, Lu CY, Chang LY, et al. Survey of pertussis in patients with prolonged cough. J Microbiol Immunol Infect. 2006;39(1):54-8.

8. Dalby T, Harboe ZB, Krogfelt KA. Seroprevalence of pertussis among Danish patients with cough of unknown etiology. Clin Vaccine Immunol. 2010; 17(12):2016-23. https://doi.org/10.1128/CVl.00270-10.

9. Lee SY, Han SB, Kang JH, Kim JS. Pertussis prevalence in Korean adolescents and adults with persistent cough. J Korean Med Sci. 2015;30(7):988-90. https://doi.org/10.3346/jkms.2015.30.7.988.

10. Lai K, Pan J, Chen R, et al. Epidemiology of cough in relation to China. Cough. 2013;9(1):18

11. Lai KLB, Wang F, Chen R, Liu X, Zhong N. Survey on the diagnosis and management of the patients with chronic cough. Int J Respir. 2011;31:645-7.

12. Christian C, Burger C, Claassens M, Bond V, Burger R. Patient predictors of health-seeking behaviour for persons coughing for more than two weeks in high-burden tuberculosis communities: the case of the Western cape, South Africa. BMC Health Serv Res. 2019;19(1):160. https://doi.org/10.1186/s12913019-3992-6.

13. Senkoro M, Hinderaker SG, Mfinanga SG, Range N, Kamara DV, Egwaga S, et al. Health care-seeking behaviour among people with cough in Tanzania: findings from a tuberculosis prevalence survey. Int J Tuberc Lung Dis. 2015; 19(6):640-6. https://doi.org/10.5588/ijtld.14.0499.

14. Senbeto M, Tadesse S, Tadesse T, Melesse T. Appropriate health-seeking behavior and associated factors among people who had cough for at least two weeks in Northwest Ethiopia: a population-based cross-sectional study. BMC Public Health. 2013;13(1):1222. https://doi.org/10.1186/1471-24 58-13-1222.

15. Chanda-Kapata P, Kapata N, Masiye F, Maboshe M, Klinkenberg E, Cobelens $F$, et al. Health seeking behaviour among individuals with presumptive tuberculosis in Zambia. PLoS One. 2016;11(10):e0163975. https://doi.org/1 0.1371/journal.pone.0163975.

16. Satyanarayana S, Nair SA, Chadha SS, Sharma G, Yadav S, Mohanty S, et al. Health-care seeking among people with cough of 2 weeks or more in India. Is passive TB case finding sufficient? Public Health Action. 2012;2(4):157-61. https://doi.org/10.5588/pha.12.0019.

17. Godfrey-Faussett P, Kaunda H, Kamanga J, van Beers S, van Cleeff M, Kumwenda-Phiri R, et al. Why do patients with a cough delay seeking care at Lusaka urban health centres? A health systems research approach. Int J Tuberc Lung Dis. 2002;6(9):796-805.

18. Addisu Y, Birhanu Z, Tilahun D, Assefa T. Predictors of treatment seeking intention among people with cough in east Wollega, Ethiopia based on the theory of planned behavior: a community based cross-sectional study. Ethiop J Health Sci. 2014;24(2):131-8. https://doi.org/10.4314/ejhs.v24i2.5.

19. Fei $Y$, Wang JM, Zhang JH, Gu QH. Access to tuberculosis care among community patients with chronic cough in Yangzhong County, Jiangsu Province. J Hygiene Res. 2006;35(2):155-8.

20. Fochsen G, Deshpande K, Diwan V, Mishra A, Diwan VK, Thorson A. Health care seeking among individuals with cough and tuberculosis: a populationbased study from rural India. Int J Tuberc Lung Dis. 2006;10(9):995-1000.

21. Hu Y, Xu B, Zhao Q, et al. Health seeking behaviors and expenditures for chronic cough in outpatients of county general hospitals in northern rural Jiangsu province. Fudan Univ J Med Sci. 2006;01:39-43.

22. Qingwu Jiang, Biao Xu, Jie Tang et al. Analysis of medical-seeking behavior and influencing factors of patients with chronic cough in Jiangsu rural areas. Supplement to Volume 25 of 2003 Chinese Journal of Antituberculosis-2003 National Academic Conference of China National Antituberculosis Association Proceedings. 2003.
23. Liu W, Yu Q, Yue H, et al. The gender difference and hospitalizing behavior of Pafients with chronic cough in Lanzhou. Chinese Primary Health Care. 2017;31(10):37-40

24. Chen Z, Peto R, Zhou M, lona A, Smith M, Yang L, et al. Contrasting male and female trends in tobacco-attributed mortality in China: evidence from successive nationwide prospective cohort studies. Lancet. 2015;386(10002): 1447-56. https://doi.org/10.1016/S0140-6736(15)00340-2.

25. Thorson A, Hoa NP, Long NH. Health-seeking behaviour of individuals with a cough of more than 3 weeks. Lancet. 2000;356(9244):1823-4. https://doi. org/10.1016/S0140-6736(00)03241-4.

26. French CT, Fletcher KE, Irwin RS. Gender differences in health-related quality of life in patients complaining of chronic cough. Chest. 2004;125(2):482-8. https://doi.org/10.1378/chest.125.2.482.

27. French $\mathrm{CT}$, Fletcher KE, Irwin RS. A comparison of gender differences in health-related quality of life in acute and chronic coughers. Chest. 2005; 127(6):1991-8.

28. Chikovore J, Hart G, Kumwenda M, Chipungu GA, Desmond N, Corbett L. Control, struggle, and emergent masculinities: a qualitative study of men's care-seeking determinants for chronic cough and tuberculosis symptoms in Blantyre, Malawi. BMC Public Health. 2014;14(1):1053. https://doi.org/10.11 86/1471-2458-14-1053.

29. Koskela HO, Lätti AM, Pekkanen J. The impacts of cough: a cross-sectional study in a Finnish adult employee population. ERJ Open Res. 2018;4(4): 00113-2018.

30. Kapaskelis AM, Vouloumanou EK, Rafailidis PI, Hatzopoulou P, Nikita D, Falagas ME. High prevalence of antibody titers against Bordetella pertussis in an adult population with prolonged cough. Respir Med. 2008;102(11): 1586-91. https://doi.org/10.1016/j.rmed.2008.06.001.

31. Senzilet LD, Halperin SA, Spika JS, et al. Pertussis Is a Frequent Cause of Prolonged Cough IIIness in Adults and Adolescents [J]. Clin Infect Dis. 2001; 32(12):1691-7.

32. Banerji D, Andersen S. A sociological study of awareness of symptoms among persons with pulmonary tuberculosis. Bull World Health Organ. 1963;29(5):665-83.

33. Blaiss MS, Dicpinigaitis PV, Eccles R, Wingertzahn MA. Consumer attitudes on cough and cold: US (ACHOO) survey results. Curr Med Res Opin. 2015; 31(8):1527-38. https://doi.org/10.1185/03007995.2014.1002558.

34. Koskela HO, Lätti AM, Pekkanen J. Risk factors for repetitive doctor's consultations due to cough: a cross-sectional study in a Finnish employed population. BMJ Open. 2019;9(6):e030945. https://doi.org/10.1136/ bmjopen-2019-030945.

35. Liu D, Yang F, Ren Q, et al. Gender differences in health seeking behaviour and tuberculosis care access of potential TB patients. Chinese Primary Health Care. 2006;20(10):58-60.

36. Biao Xu, Yang Fei, Qi Zhao. The impact of medical treatment of patients with chronic cough in rural communities on the detection of tuberculosis patients. National Academic Conference of Chinese Antituberculosis Association. 2007.

37. Fujimura M. Frequency of persistent cough and trends in seeking medical care and treatment-results of an internet survey. Allergol Int. 2012;61(4):57381. https://doi.org/10.2332/allergolint.11-OA-0368.

38. Moore A, Ashdown HF, Shinkins B, Roberts NW, Grant CC, Lasserson DS, et al. Clinical characteristics of pertussis-associated cough in adults and children: a diagnostic systematic review and meta-analysis. Chest. 2017; 152(2):353-67. https://doi.org/10.1016/..chest.2017.04.186.

39. Assefa Y, Woldeyohannes S, Gelaw YA, Hamada Y, Getahun H. Screening tools to exclude active pulmonary TB in high TB burden countries: systematic review and meta-analysis. Int J Tuberc Lung Dis. 2019;23(6):72834. https://doi.org/10.5588/ijtld.18.0547.

\section{Publisher's Note}

Springer Nature remains neutral with regard to jurisdictional claims in published maps and institutional affiliations. 